\title{
Research on Talent Cultivation Model of Chinese Medical Education based on International Standards
}

\author{
yanchun $\mathrm{Qi}^{1, \mathrm{a}}$, Deqing Cai ${ }^{1, \mathrm{~b}}$ \\ ${ }^{1}$ Gannan Medical University, Ganzhou, Jiangxi, 341000 \\ ${ }^{a}$ email , ${ }^{b}$ email
}

Keywords: International Talent Standard, Chinese Medical Education, Cultivation Model

\begin{abstract}
The training mode of medical talents is the key to the reform of medical education. The purpose of this study is to study the development course, current situation and future trend of higher medical education personnel training. This paper analyzes the history and current situation of the training mode of higher medical education talents in our country and the reform of the training mode of foreign advanced medical education talents, and expounds the necessity and urgency of this research.
\end{abstract}

\section{Introduction}

With the rapid development of modern communications, transportation and technology and the trend of world economic integration, the world is gradually merging into a global village. In this "global community", many of the technology shared by all mankind has adopted the same technical specifications, modern society, such as transportation, shipping, telecommunications, insurance, accounting, lawyers, have adopted a common standard of practitioners. Medicine is also a global professional,: ll: the community around the residents, regardless of race, class, age, gender, are inseparable from the job. At the same time, the doctor is the world's oldest and most widely needed career, it is related to the world's most precious non-renewable resources one by one life and health. Today, about 6 million doctors who provide medical care for more than 6 billion inhabitants worldwide have graduated from more than 1,600 medical schools around the world. In the trend of economic globalization, medical knowledge and scientific research has crossed the traditional borders, doctors cross-border exchanges and activities are more and more frequent. But for a long time, the standards and requirements of medical education in different countries and regions have not been systematically compared and studied in terms of standards and requirements, such as Zongru and the Japanese standard, educational plan, knowledge, skills, professional attitude, ethics and values. There is no definition of the core or at least the ability of the physician. With the concept of the global village is widely accepted, it should be said that the global medical education of international standards and the most basic requirements of the study and implementation of the time is ripe. The development of various multilateral agreements and treaties has also opened the door for global exchanges, accelerating the pace of development of common educational standards, and promoting mutual recognition of the qualifications of professionals and the issuance of licenses.

\section{History and Current Situation of Personnel Training Model in Higher Medical Education}

Ancient medical education, with ancient philosophy of philosophy to master the medical theory, mainly from the practical experience of the summary, summarized as clinical knowledge, mostly mentoring system, and the feudal system strongly around the training objectives and interpersonal relationships in educational activities. This model is like the farmer cultivating crops under the natural economic conditions, operating simply and experimentally with a very limited goal. China's ancient medical education has always been taught mentoring. The cultivation mode of this kind of medical talents has been eliminated by history, but it can be seen in the overall view of the content of education, reflecting the embryonic form of personality education and pay attention to practical characteristics.

After the founding of the People's Republic of China, in accordance with the principles of 
socialism, and with reference to the experience of the former Soviet Union, step by step to the reform of the old medical education, higher medical education personnel training model is further reform: the original comprehensive university medical school ) All changed to independent medical institutions. And to build a number of medical colleges and universities (including the creation of Chinese medicine college, in order to adapt to the national economic development and medical and health needs, modeled on the former Soviet Union applicable expert training mode, professional categories increased, smaller, new health, pediatrics, , Traditional Chinese medicine and other professional, basically has been followed so far, this traditional medical education personnel training model with a systematic, stable, solid theoretical teaching, with a small amount of input and output of a large number of medical graduates, and triggered a There are at least two interrelated ideas that are firmly rooted in the minds of medical educators, and they are: (1) clinical capacity is based on the study of basic medical knowledge for two consecutive years; (2) Hypothesis deductive reasoning process will serve as a basis for cultivating basic cognitive habits, so that students become independent, sustained and self-directed clinical problem-solving. This model has its historical necessity. China's health staff supply and demand, health services need to be popular and other issues contributed, but because of its practical characteristics, medical education requirements Physical and physical development of students are subject to great restrictions, and at least there are three main problems: First, the clinical pre-course with clinical training is completely separated, the students in the first two years of learning did not touch the real Patients, and secondly, although the boundaries of preclinical and clinical training sessions are clear, the order of the basic medical courses taught is seldom paid attention to. Therefore, students not only want to remember more and more Order information, and they are in the absence of a complete clinical experience in the case, the clinical useful basic knowledge together; third, by each department to control their teaching content, it seems that the system is in the training of the Disciplines of small scientists, and ultimately become a scientific medical workers in view of the above situation, eventually led to the interdisciplinary, organ system-based curriculum model development and comprehensive development of medical talent training model development.

\section{Training Mode and Characteristics of Medical Talents}

In the second half of the twentieth century, the analysis of the factory type or the traditional training mode, encountered difficult to overcome the sharp contradictions: biomedical model to the biological) psychological transformation of the medical model, medical science to the rapid development of comprehensive differentiation, As the center of the curriculum and its content is growing up, analytical teaching overwhelmed, students in the passive learning of the state and difficult to develop independently; social rapid development and changes, including medical students, including educators put forward higher requirements, Not only to have the ability to engage in professional work, but also need to have a good psychological quality and development and development capabilities, which still according to the factory type in a certain box, procedural training has been unable to adapt, all superimposed education can not reach Organic integrity and personality of the full development of the requirements. In order to overcome these contradictions, medical educators launched a difficult exploration and practice. Looking at the orientation: First, moral, intellectual, physical education in three aspects of organic integration, deepening or breaking the boundaries of traditional disciplines, concise teaching content, strengthen the organic combination; Second, strengthen the ability to cultivate, improve the society and learn Can continue to develop capacity; third is to integrate all aspects of education, play the benefits of education, thus achieving the training of medical talents with good quality, and strive to change from the type of reproduction to create. This is summarized as a comprehensive development.

As a result of the development of culture, humanities, social factors and their relationship with the development of changes in medical talent training model has also experienced by the simple analytic - integrated, mentoring individual training - unified scale training - both the scale of cultivation and focus on the development of individual development history The evolution of the process, its training objectives are also limited by the target - unified regulatory goals - to adapt to 
the evolution of social development goals. China's current higher medical education curriculum and teaching content, the introduction of the former Soviet Union, but also the introduction of the West and our own, but its important feature is basically based on the traditional biomedical model, medical personnel training mode still Basically follow the traditional model, its inherent contradictions in the new situation has recently highlighted. China's higher medical education in the 21st century must reform and innovate and establish a talent training mode that adapts to social development and adapts to international development trends. Its goal is to cultivate a wide range of knowledge, solid foundation, strong ability, high quality, innovative modern medical talents. To this end, based on the experience of higher medical education reform and higher education reform at home and abroad, based on national conditions, efforts to reform the existing medical personnel training model to solve the characteristics of professional education and modern student employment diversity orientation is inconsistent The contradiction.

\section{The Basic Tactics of the Reform of Talents Training Mode in Higher Medical Education}

Renewing the educational concept is the forerunner of the educational reform, and the key to the cross-century educational reform lies in the change of the talent training mode. One of the key points in updating the concept of education is to enhance the quality of personnel training concept, the second is to establish a comprehensive quality training concept. Now has entered the era of knowledge economy, the requirements of talent is a broad knowledge and solid foundation. New scientific and technological achievements are often a variety of professional, interdisciplinary, infiltration, integration of the results. Therefore, in the university education stage, should be wide caliber training students, medical education is also the same, modern medical education is the basic education of the school - after graduation medical education - continuing medical education composed of three stages of continuous continuum. Medical students in the medical college undergraduate education stage is to make it eventually become a qualified doctor of professional basic education, graduation was not qualified doctors, engaged in health practice required professional ability, must go through a lot of work after graduation Practice and strict standardization of professional training to gradually grasp. Therefore, both from the social adaptability of medical graduates, or from the high quality of the growth of medical talent point of view, should be in the medical undergraduate education stage of the implementation of wide caliber Tongke medical education.

Reasonable curriculum structure system is the basis of reforming the training mode of medical talents, establishing the curriculum structure system which is compatible with the requirements of economic system and social development, has been paid by many countries and adopted a series of effective measures. Reform the teaching content. The reform of teaching content directly reflects the purpose of education and training objectives, is to improve the quality of personnel training at the core. (1) We introduce new science, emergency medicine, community medicine, health management and other contents of social science by introducing new discipline, edge discipline and interdisciplinary teaching in time. (2) to establish the basic knowledge, theory, skills as the focus of teaching content, while actively absorbing the new achievements in medical science and technology. (3) Reduced verification and demonstration experiments on experimental courses, increased exploratory and comprehensive experiments. Especially in the case of financial and equipment difficulties, how to optimize the experimental content, improve the quality of the experiment, so that the full use of resources, do not blindly pursue the proportion of theory and experiment.

Innovative methods and means of education. China's current part of the medical school has carried out a problem-based teaching method of reform. Based on the problem-based, student-centered, teacher-led group discussion teaching method has obvious advantages in cultivating students' basic clinical skills than traditional methods, and can motivate students to learn the enthusiasm and initiative to cultivate and improve their Self-learning ability, take the initiative to acquire knowledge skills, change students' old learning methods, improve teaching efficiency. It is not only to realize the sharing of teaching resources, but also to promote the students' self-study, to enhance the interest of learning, to create an intuitive, vivid and lively teaching environment, and 
to improve the learning effect and efficiency of the audiovisual teaching, computer-aided teaching and multimedia network teaching. The establishment of a high-quality teacher team is the implementation of quality education, the existing medical talent training model to reform the fundamental. China Education Reform and Development Program 6 clearly stressed: the hope of revitalizing the nation in education, the hope of revitalizing education in the teacher, to establish a good political, professional quality, reasonable structure, relatively stable teacher team is the fundamental education reform and development Plan. It is difficult to adapt to the needs of high-quality medical talents in the 21st century. Therefore, it is urgent to strengthen the construction of teaching staff and improve the overall quality of all teachers. It is difficult to adapt to the needs of high-quality medical talents in the 21st century.

\section{Conclusion}

With the popularity of China's higher medical education standards, medical personnel training model has begun to move in the direction of internationalization. Higher medical education reform long way to go, all aspects of the more difficult, facing a serious challenge. We must take the initiative to adapt to the development of medical science, the transformation of medical model and the need for health reform, and gradually form a Chinese characteristic, effective clinical medical personnel training system, and strive to cultivate new medical talents, to adapt and promote China Economic development and social progress.

\section{References}

[1] Liu Bin, Wang Jiayao. Analysis of American medical education [J]. Chinese Journal of Social Medicine, 2007 (01)

[2] Huang Zijie, Wu Yinxin. Foreign medical education model and the reform of medical education in China [J]. Northwest Medical Education, 2007 (04)

[3] Wang Haiwei, Wang Hong, Shen Mingda, Weng Shengxin, Tian Guang. American medical education system on China's clinical teaching model of the enlightenment [J]. Journal of PLA Hospital Management, 2006 (02)

[4] Yang Mianhua, He Ping. Education practice around the international standard of medical education talent training model [J]. Chinese Journal of Medical Education, 2006 (02)

[5] Wang Qing. Reform and innovation: nearly half a century of American medical education [J]. Fudan Education Forum, 2006 (05) 